\title{
MICROCONTROLLER BASED AUTOMATIC CONTROL FOR WATER PUMPING MACHINE WITH WATER LEVEL INDICATORS USING ULTRASONIC SENSOR
}

\author{
J. E. Okhaifoh ${ }^{1}$, C. K. Igbinoba ${ }^{2}{ }^{*}$ and K. O. Eriaganoma ${ }^{3}$ \\ 1, 2, 3 DEPT. of EleCtriCAl AND ElECTRONICS ENGINEERING, FEDERAL UNIVERSITY OF PETROLEUM RESOURCES, NIGERIA \\ E-mail addresses: ${ }^{1}$ okhaifor.ebosetale@fupre.edu.ng, ${ }^{2}$ igbinoba.charles@fupre.edu.ng, ${ }^{3}$ kelisco04@gmail.com
}

\begin{abstract}
Water scarcity is one of the major problems facing some cities of the world and wastage during transmission has been identified as a major problem. In this paper a Microcontroller Based Automatic Control for Water Pumping Machine and Level Indicator (MBACWPMLI) has been designed, constructed and tested. The MBACWPML I uses the reflection of sound (echo) to give the indication of water level in a storage tank and also the automatic control of the water pumping machine. The MBACWPMLI uses ultrasonic sensor installed at the top of a tank to send and receive sound waves, and the time taken is converted to distance by the microcontroller to give corresponding digital outputs which turns ON LEDs that indicate the level of water in the storage tank. The microcontroller also gives digital output to turn ON the water pump (when the water in the tank is at a preset minimum level of 0.27 metres) or turn OFF the water pump (when the water goes above the chosen maximum level of 0.05 metres). The MBACWPMLI when tested turned ON or OFF the water pump at the preset minimum and maximum level and the required LEDs were also turned $O N$ at the corresponding water level.
\end{abstract}

Keywords: Water level, microcontroller, water pump, level indicator, Ultra sonic Sensor, LED

\section{INTRODUCTION}

Water is a common chemical substance that is most essential to man for survival as it forms an average of $60 \%$ of the human body $[1,3,4]$. Although water forms a larger mass of the earth, it is not readily available to man for use as a result of its composition and distance from place of necessity. This has led to efforts to store and retrieve it when needed by the development of various water storage schemes or systems such as dams, reservoirs, wells, artificial lakes, etc., which engage the use of an electric pump to aid its transportation during storage and retrieval [5, $6,7]$. Water is pumped from its source (lower surface) to where it is stored and treated (higher surface) after which it is distributed by gravity or pumped to where it is needed (places of utility) usually at different surface levels.

The use of electric pumps to pump water from a source to where it is needed and during retrieval was successfully done, nevertheless with a number of shortcomings [8,9]. The shortcomings are reflected in the challenges of achieving high energy efficiency and extended lifespan of the pump by controlling when to pump, when to stop pumping and how to monitor the level of water in a storage tank. Human intelligence (which in this particular case is highly unreliable, costly, inefficient and prone to errors) was employed to address these issues. However, this led to wastage of human resources as well as the inefficient maximization of the performance and life span of the electric pump. Putting a check to these issues will require an improved operation of the electric water pump which has led to the design and development of several electric water pump controllers $[9,10]$.

The MBACWPMLI presented in this paper was designed with focus to eliminate the difficulties involved in monitoring and controlling the pump while maximizing the performance and life span of the electric water pump.

\section{REVIEW OF EXISTING SYSTEMS}

Several works has been done on the control of water pumping machine and level indication but these systems have their own disadvantages as a result of the method of sensing employed. Most of them use the electrical conductivity of water by installing metallic 
conductors at separate levels along the tank height to act as sensors. Over time, the sensor corrodes as it comes in contact with the water, thereby making it loose its electrical conductivity. This also result in reduced water quality due to contamination of the water - change in the $\mathrm{pH}$ level, introduction of stains, colourations, deposits and change in taste of the water. In general, the water becomes unhygienic for use and hazardous to health over time. The proposed system addresses these shortcomings as it uses ultrasonic sensor as its sensing device which do not come in contact with water.

\section{METHODOLOGY}

In order to achieve the aim set out, some water supply schemes were studied. The various electric water pump controllers developed for these water schemes were studied and various design options and their cost implications were considered [2, 5, 8, 9, 11 - 13]. The system was designed using proven electrical and electronic principles with focus on reducing complexity, hence reduced high cost and energy requirement [2]. It was broken down into four sections: the power supply unit, the sensing unit, control unit and the switching/output unit.

The device uses an ultrasonic sensor installed at the top of the storage tank which is triggered by the microcontroller to send and receive sound waves, and the time it takes to send and receive the signal is converted to distance to give out corresponding digital outputs which will be used by the microcontroller to drive digital outputs.

The microcontroller is programmed to send a pulse of $10 \mu$ s to the trigger pin of the sensor, after which the sensor is enabled to send and receive an $8 \times 40 \mathrm{KHz}$ sound wave. When the water level rises, the time it takes to send and receive the sound waves is converted to distance by the microcontroller using the expression of equation (1) at the bottom of this page.

The value of the distance is compared with the preset distance in the program and when it get to a preset distance the microcontroller gives a digital output to turn ON an LED. A program was written using the arduino Integrated Development Environment (IDE) in C programming Language into the microcontroller for control and coordination of the system functions.

The height of tank used for this design is 0.30 metres and using equation 1 , the different levels are calculated as shown in table 1.
Table 1: Water level sensing

\begin{tabular}{ccc}
\hline Water level & $\begin{array}{c}\text { Distance from } \\
\text { Sensor }(\mathrm{D}, \mathrm{m})\end{array}$ & $\begin{array}{c}\text { Time taken }(\mathrm{T}, \\
\mathrm{ms})\end{array}$ \\
\hline Minimum level & 0.27 & 1.59 \\
Level 1 & 0.25 & 1.47 \\
Level 2 & 0.20 & 1.18 \\
Level 3 & 0.15 & 0.88 \\
Level 4 & 0.10 & 0.59 \\
Maximum level & 0.05 & 0.29 \\
\hline
\end{tabular}

\section{PRINCIPLE OF OPERATION OF THE MBACWPMLI}

Fig. 2 shows the detailed circuit diagram of the MBACWPMLI. All components were powered by either $12 \mathrm{~V}$ or $5 \mathrm{~V}$ as the case may be. The sensor is an Ultra Sonic Sensor mounted at the top of the tank. Assuming the tank is empty when the system is switched ON, the microcontroller sends a pulse of $10 \mu$ s to the trigger pin of the sensor. The sensor then transmit an $8 \times 40$ $\mathrm{KHz}$ sound wave to enable the echo pin, the reflected sound wave is receive to disable the echo pin. The time it takes to transmit and receive the sound wave is used by the microcontroller to calculate the distance. If the distance calculated is less than or equal to the preset minimum distance, the pumping machine is automatically switched $\mathrm{ON}$ and the process continues. Again, the microcontroller sends another pulse of $10 \mu$ s to the trigger pin of the sensor, the sensor then transmit an $8 \times 40 \mathrm{KHz}$ sound wave to enable the echo pin, the reflected sound wave is received to disable the echo pin. The time it takes to transmit and receive the sound wave is used by the microcontroller to calculate the distance. If the distance calculated is greater than the preset minimum distance and less than or equal to the preset distance of LEVEL 1, LED 1 is switched ON. This process continues until the maximum level is reached to automatically switch OFF the pumping machine.

As the water level decreases, the time it takes to transmit and receive the sound wave is continuously used by the microcontroller to calculate the distance; the distance calculated is compared with the preset distance. Assuming the water level decreases below the preset maximum distance, LED 5 remains switched $\mathrm{ON}$ and pumping machine remains switched OFF. When the water level decreases below LEVEL 4, LED 5 goes OFF and the pumping machine remained switched OFF. When the water level decreases below the preset minimum distance, LED 1 goes OFF and the pumping machine is automatically switched $\mathrm{ON}$.

$$
\text { Distance }=((\text { ECHO high level time } \times \text { Ultrasonic velocity }) / 2)
$$




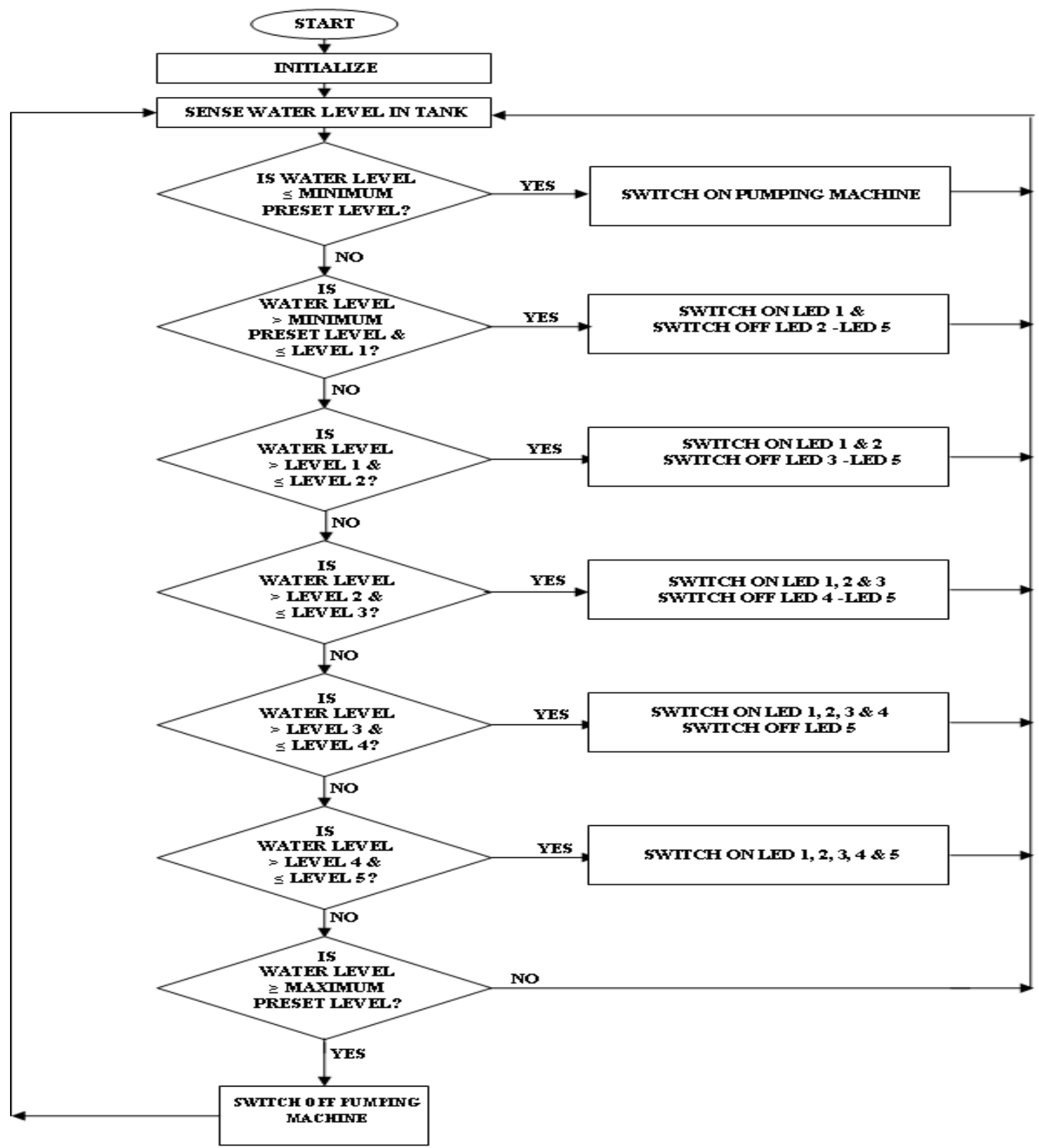

Fig. 1: Flow chart of the Microcontroller Based Automatic Control for Water Pumping Machine and level indicator

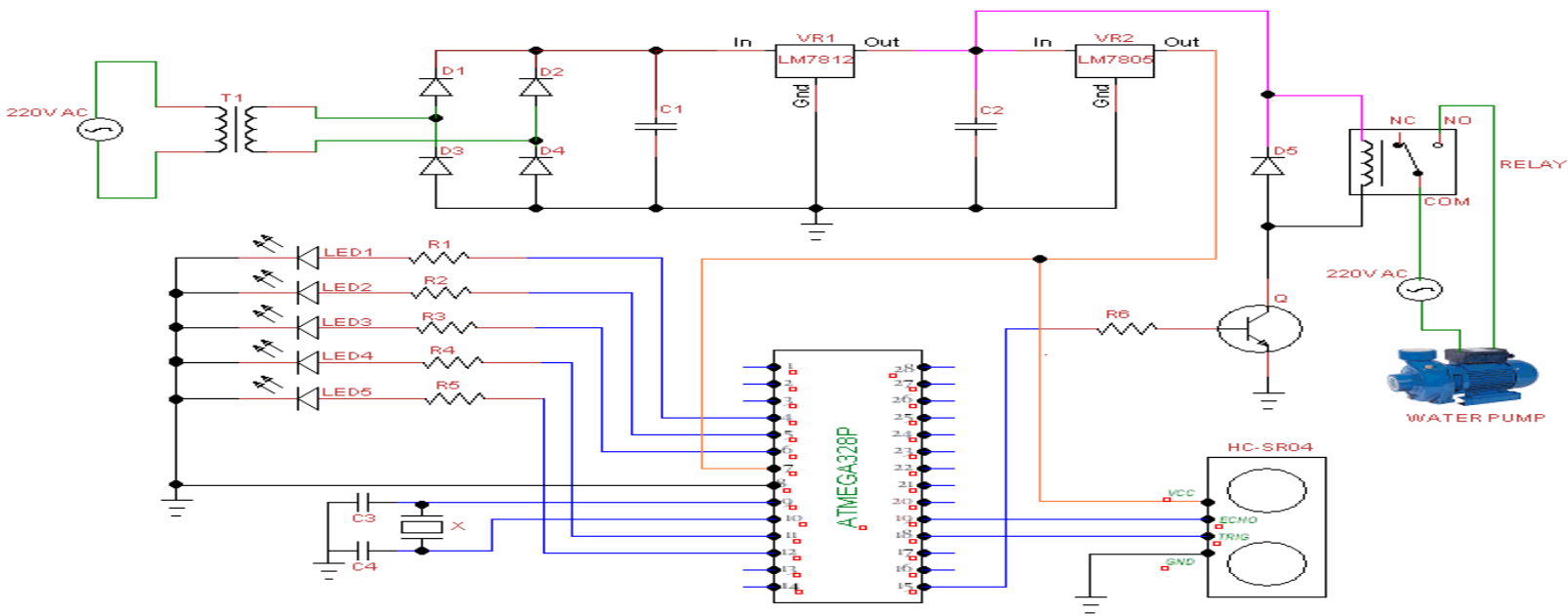

Fig.2: Complete circuit diagram of the microcontroller based automatic control for water pumping machine with water level indicators 

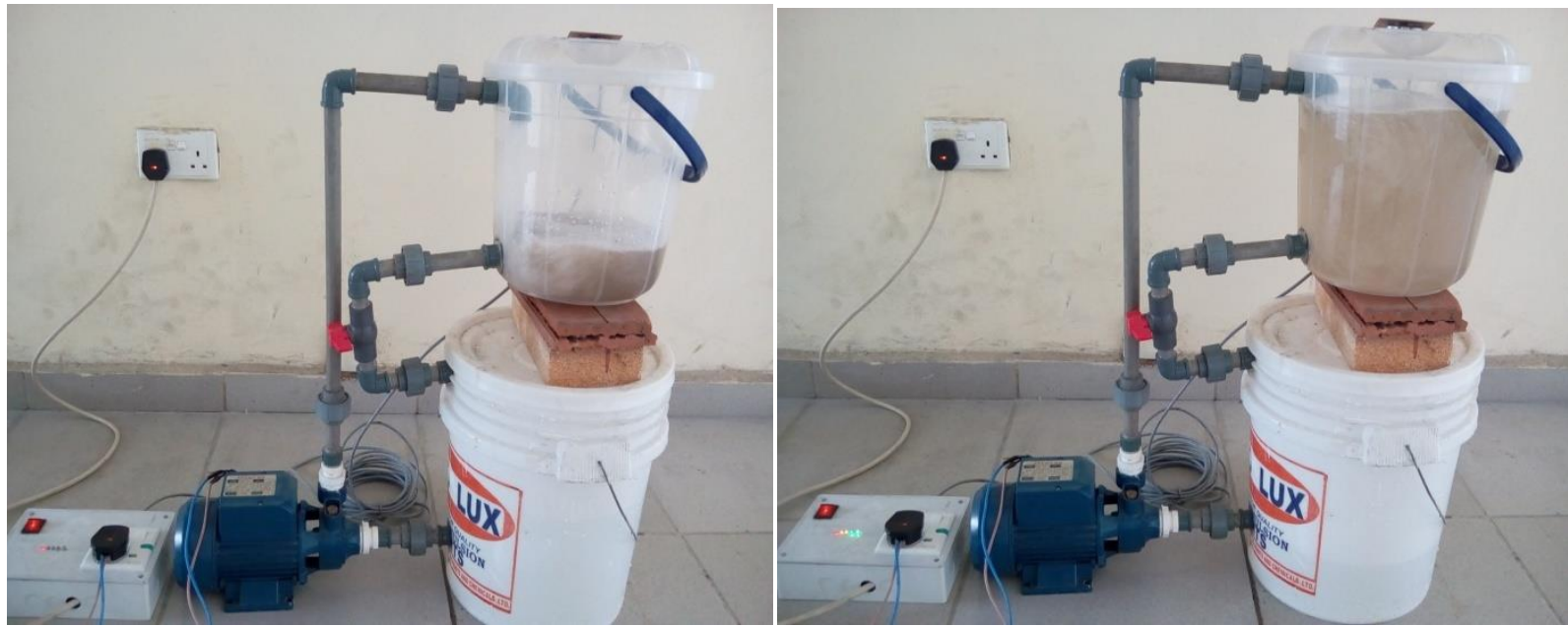

Fig. 3: Pictorial view of the system under test

Table 2: Summary of test results as water level increases

\begin{tabular}{|c|c|c|c|c|c|c|}
\hline \multirow{2}{*}{$\begin{array}{l}\text { Water level in Tank } \\
\text { (Metres) }\end{array}$} & \multicolumn{5}{|c|}{ Light Emitting Diodes (LEDs) state } & \multirow{2}{*}{ Pumping Machine State } \\
\hline & LED 1 & LED 2 & LED 3 & LED 4 & LED 5 & \\
\hline$\leq$ minimum & OFF & OFF & OFF & OFF & OFF & ON \\
\hline$>$ minimum $\& \leq$ level 1 & ON & $\mathrm{OFF}$ & OFF & OFF & $\mathrm{OFF}$ & ON \\
\hline$>$ level $1 \& \leq$ level 2 & ON & ON & OFF & OFF & OFF & ON \\
\hline$>$ level $2 \& \leq$ level 3 & ON & ON & ON & OFF & OFF & ON \\
\hline$>$ level $3 \& \leq$ level 4 & ON & ON & ON & ON & OFF & ON \\
\hline$>$ level $4 \&<$ maximum & ON & ON & $\mathrm{ON}$ & ON & ON & ON \\
\hline$\geq$ maximum & ON & ON & ON & ON & ON & OFF \\
\hline
\end{tabular}

Table 3: Summary of test results as water level decreases.

\begin{tabular}{lcccccc}
\hline \multirow{2}{*}{$\begin{array}{c}\text { Water level in Tank } \\
\text { (Metres) }\end{array}$} & \multicolumn{4}{c}{ Light Emitting Diodes (LEDs) state } & \multirow{2}{*}{ Pumping Machine State } \\
\cline { 2 - 5 } & LED 1 & LED 2 & LED 3 & LED 4 & LED 5 & \\
\hline$<$ maximum\& $>$ level 4 & ON & ON & ON & ON & ON & OFF \\
$\leq$ level 4\& $>$ level 3 & ON & ON & ON & ON & OFF & OFF \\
$\leq$ level 3\& $>$ level 2 & ON & ON & ON & OFF & OFF & OFF \\
$\leq$ level 2 \& $>$ level 1 & ON & ON & OFF & OFF & OFF & OFF \\
$\leq$ level 1 \& $>$ minimum & ON & OFF & OFF & OFF & OFF & OFF \\
$\leq$ minimum & OFF & OFF & OFF & OFF & OFF & ON \\
\hline
\end{tabular}

\section{TEST AND RESULTS}

Tables 2 and 3 shows a summary of the test results. A water source was used to supply water to the pumping machine which was connected to a water storage tank. The water storage tank was made of a transparent container. When the system was connected to 240 VAC supply and powered ON, the pumping machine was automatically switched $\mathrm{ON}$ and the LEDs came $\mathrm{ON}$ as the water rises to their respective levels. When the water rose to the maximum point, the pumping machine was automatically switched OFF.

\section{CONCLUSION}

This work unveils the design and implementation of a Microcontroller Based Automatic Control for Water Pumping Machine and Level Indicator (MBACWPMLI) using ultrasonic sensor. It gives digital output which turns $\mathrm{ON}$ the water pump when the water in the tank is at a preset minimum level of 0.27 metres and turns OFF the water pump when the water is above the chosen maximum level of 0.05 metres. Performance evaluation of the system from test results shows that the system is highly efficient since it's eliminates the unreliability of humans, and also improves the workable lifespan of the pumping machine by controlling when to switch ON and Switch OFF the pumping machine. 


\section{REFERENCES}

[1]Benelam, B. and Wyness, L. "Hydration and Health: A Review", British Nutrition Foundation, Nutrition Bulletin, Vol. 35, pp. 3-25, 2010

[2] Ikponmwosa, 0. and Charles, A. "Development of an electric water pump controller and level indicator," International Journal of Engineering and Applied Sciences, Vol. 3, Number 2, April 2013, pp. 18-21. 2013.

[3] Jequier, E. and Constant, F. "Water as an essential nutrient: the physiological basis of hydration," Eur J Clin Nutr, Vol. 64, Number 2 2010, pp. 115-123.

[4] Popkin, B. M., D'Anci, K. E. and Rosenberg, I. H. "Water, hydration, and health," Nutr Rev, Vol. 68, Number 8, 2010, pp. 439-458.

[5] Maurice, M. and Shona, R. "Community Governance for Sustainability: Exploring Benefits of Community Water Schemes," Local Environment, Vol. 12, Number 4, , pp. 437-445. 2007

[6] Vikram, S., Gosain, A. K., Datta, P. S. and Diwan, S. "A new schem.e for large-scale natural water storage in the floodplains: the Delhi Yamuna floodplains as a case study," Current Science, Vol. 96, Number 10, 2009, pp. 1338-1341.

[7] Bouarfa, S., Vincent, B., Wu, J., Yang, J. and Zimmer, D. "Role of groundwater in irrigation water management in the downstream part of the yellow river," Irrigation and Drainage Systems, Vol. 20, 2006, pp. 247-258.

[8] Chaiko, Y., Zhiravecka, A., Kunicina, N., Galkina, A. and Ribickis, L. "Modelling decision making procedure for pump electric drives chosen for water pump stations," Electronics and Electrical Engineering, Vol. 82, Number 2, 2008, pp. 59-64.

[9] Wara, S. T., Orovwode, H. E. and Mohammed, O. A. "Design Construction and Simulation of an Electronic Water Level Controller," International Research Journal in Engineering Science and Technology, Vol. 4, Number 1, 2007, pp. 107-108.

[10] Engineered Systems, "Pump Controllers," BNP Media, 2013. [Online]. Available: http://www.esmagazine.com/search?q=Pump+co ntrollers. [Accessed on February 10, 2016].

[11] Khaled Reza, S. M., Ahsanuzzaman, S., Tariq, M. and Mohsin Reza, S. M. "Microcontroller Based Automated Water Level Sensing and Controlling: Design and Implementation Issue", Proceedings of the World Congress on Engineering and Computer Science, Vol. 1, October 2010.

[12] Ali, A., Al_Soud, M., Abdallah, E. and Addallah, S. "Water Pumping System with PLC Frequency and Frequency Control", Jordan Journal of Mechanical and Industrial Engineering, Vol. 3, Number 3, 2009, pp. 216-221.

[13] Ebere, E. V. and Francisca, 0. O. "Microcontroller Based Automatic Water Level Control System", International Journal of Innovative Research in Computer and Communication Engineering, Vol. 1, Number 6, August 2013, pp. 1390-1396.

[14] John, J. T. and Richard, W. M. "Measured Performance and Impacts of Drop-In Residential Heat Pump Water Heaters", ASHRAE Transaction: Symposia: NA-04-5-2, pp. 664-670, 2004. 